\title{
CROSS CULTURAL COMMUNICATION TO ACCOMODATE GENERATION GAP IN DISRUPTIVE ERA
}

\author{
Bhernadetta Pravita Wahyuningtyas ${ }^{1,2}$, Ulani Yunus ${ }^{1,2}$, Mario Nugroho Willyarto ${ }^{2,3}$ \\ bhernadetta@gmail.com \\ ${ }^{1}$ Communication Department, Faculty of Economic and Communication, Bina Nusantara Univer- \\ sity \\ ${ }^{2}$ Research Interest Group of Cross-Cultural Communication, Bina Nusantara University \\ ${ }^{3}$ Language Center, Industrial Engineering Department and Faculty of Humanities, Bina Nusantara \\ University
}

\begin{tabular}{l} 
Article Info \\
\hline Cross-Cultural Communication, \\
Communication Accommodation, \\
Social Structure, Disruptive Era, \\
Bina Nusantara University
\end{tabular}

\section{INTRODUCTION}

Change is always been a reality in our life. But nowadays, various changes in business, socializing, and truth seeking are carried out by means of different new interactions. Everyone is trying, digging deeper, observing more, struggling to follow, and some even tried to create the breakthrough. Many people thinking that change is a frightening process which create anxiety and uncertainty feelings (Carleton, 2016). Change is sometimes seen as the process of destroying existing defaults, through innovation, business models, and disruption. Nowadays, the pandemic suddenly changed all things in our life, including the teaching and learning process in university. Due to the different level of un-

\begin{abstract}
This research described about how Cross-Cultural Communication contributes its influence on accommodating the generation gap to improve a social structure in Indonesia, especially on Disruptive Era. In accommodating the generation gap, the cross-cultural communication focus on the patterns of convergence and divergence social approval, communication efficiency, and identity. This research was done in constructivism paradigm, and coding to analyze the data. The results showed that accommodation in cross-cultural communication can improved the ability on prob $\square$ lem-solving skills, collective decisions and can resolved the problem that arise from generation gap to make it become harmonious interactions. The lack of the role in providing information from generation to another generation usually based on the assumption that the other generation already knew the condition, situation and also further. Due to the changes in social structure, BINUS creating a cross cultural openness, and engagement, through (for example) creative furniture arrangemement in some classes. The result also shown that engagement between the students and the lecturer will be more powerful in creating values to have a better social condition. The people who willing to build the communication inste
successful in all aspects of cross-cultural communication.
\end{abstract}

Copyright (C) 2021 Interaksi: Jurnal Ilmu Komunikasi. derstanding and familiarity of technology between students and the lecturer, the conflict arises. The gap between them shows that each of them have their own perspectives, assumptions, and expectations, that instead of discuss it openly, their hold it by theirself, and something that maybe people not pay attention too much is that communication and technology nowadays is not value-free (Adiyanto, 2020) When there are no new ways or new paradigms that are considered good or best, then the arguing arises; people started to question and doubting each other, attacking in the difficulties encountered, instead of reinforcing and finding solutions together. Disruption itself, especially digital disruption comes with deep social changes of consumption practices and daily interactions (M., Rauch, \&

Corresponding Author:

Bhernadetta Pravita Wahyuningtyas

Communication Department, Faculty of Economic and Communication, Bina Nusantara University, Jl. K.H. Syahdan No. 9 ,

Palmerah, Jakarta Barat, 11480, Indonesia

Email:bhernadetta@gmail.com 
Wagner, 2016). Not surprisingly, it threatens the persistence not only of single path - dependent firms but even of entire world and farreaching implications of social changes, therefore we need to gain a more nuanced understanding of how we can respond to the disruptive impact.

Changing and disruption differently responded by different generation and different sector, in health sector for example, The health care sector has a significant role to play in fostering equity in the context of widening global social and health inequities (Browne, et al., 2018), therefore the disruption had viewed as the opportunity. Indonesia is an archipelago that has 33 provinces, with 6 religions (or more), and approximately 150 ethnic groups spread throughout the archipelago. Unity is a form of appreciation for the diversity that exists in this world. Diversity is not an arena of competition, but a place for socialization while all people know each other and unite to build a better country. Diversity should be maintained for it is the soul of Indonesia; this is a thing that must be celebrate. People need to learn how to interact in a diverse environment, for cultural diversity enhances the academic experience, too. There is a richness that comes from people working side by side with others who are not come from the same perspective and values.

The research was focusing on people on $\mathrm{Bi}$ nusUniversity, for university is the perfect place to observed the diversity. When students feel their beliefs and backgrounds are respected and valued, they report a stronger connection to their environment (C. Booker \& D. Campbell-Whatley, 2018). Their study shows in how faculty create an inclusive environment in the col- lege classroom setting; the interaction and bonding is obvious since the students trusted then lecturer and environment that they were respected and heard whole heartedly.

The prior data was taken from employees, lecturers, college students and businessman from $\mathrm{Bi}$ nusUniversity, but in this study we focusing on students and lecturers. The purposes of this research is to show how people can implement the cross cultural communi- cation model to their daily life, especially when they were into any specific condition as surrounded by vari- ative people by era and background.
The results showed that accommodation in crosscultural commu- nication can improved the ability on problem-solving skills, collective decisions and can resolved the prob- lem that arise from generation gap to make it become harmonious interactions. There were surely so many differences amongst generation, such as attitudes, fo- cus, and priorities. The lack of the role in providing information from generation to another generation usu- ally based on the assumption that the other generation already knew the condition, situation and also the meaning behind it as well without any discussion and deeper communication further. Due to the changes in social structure, Bina Nusantara University creating a cross cultural communication model to accommodate the generation gap in social structure and creating val- ues to have a better social condition. Each generation has their own characteristics and traits, the most im- portant thing to realized and do is learning how to ac- commodate these generations to get along together (Comperatore \& Nerone, 2008).

\section{THEORETICAL FRAMEWORK}

Methodology

This study uses the constructivism paradigm, witha phenomenological approach, an approach that gives an understanding that the world is something that is constructed intersubjective and reflects various human experience. In this study, the informants were the Binusian, who have their own experiences and perspectives. They were employees, lecturers, college students and business from Binus University. Meanwhile, the determination of informants in the study was chosen by purposive sampling. Data collection techniques used in this study are in-depthinterviews, observation, literature studies, documentation, and online searches. Triangulation used is the triangulation of data sources, namely, to eliminate differences in construction in fact during the process of collecting data concerning various eventsand relationships from various views.

According to Neuman (2013), social reality is a changing condition over time, and is the result of a form of tension, conflict and contradiction between social institutions. In the data collection techniques, this study used observational participatory: in-depth 
interviews, text analysis, secondary data, and structured interviews.

According to Bryman (2012) there are several ways to determine the validity of qualitative research data:

1. Credibility; refers to whether the research process and results can be accepted or be-lieved. In examining the validity of the data, the researchers used a technique of continuousobservation, and carefully, so that researchers could see directly and can explain social phe- nomena under study as it is. In this study, re- searchers conducted interviews and verbatim coding, so it can be analyzed accurately.

2. Transferability; refers to whether the resultsof this study can be applied to similar situa- tions or another. The concept of validity gen- eralization states that an invention may apply or be applied to all contexts within the same population on the basis of findings obtained ina representative sample represents the popula- tion. In this study presents descriptive data transferability quality, for example through the background informant and the informant's role in the institution.

3. Dependability; refers to the consistency of researchers in collecting data, forming and using concepts when making interpretations todraw conclusions. Drawing conclusions in thisstudy to be done carefully and consistentlybased on observation and in-depth interviews that have been conducted by the researchers.

4. Confirmability; refers to whether the resultscan be verified, which results in accordance with the data collected. This is done by show- ing research results re-confirm the informant or informants answer so that research results objectively.

\section{Conceptual Study}

\section{Convergence and Divergence Communication}

In a communication a person always has intention or idea and goal to carry out about what would they do. Convergence is a process where people tend toadapt the other person"s communication characteristics to reduce the social differences; whether Divergence is the process contradicts the method of adaptation and in this context the individual emphasize is on the social difference and nonverbal differences between the inter- actants.

The two processes usually are dependent on the characteristics of the interactant. People accommodatedtheir communication while interacting with a person who has higher standards and other characteristics which they believe is better than them. And the diver- gent exhibits an opposite characteristic as it emphasizes the difference among the close relations with each oth- er.

All over the world nowadays have younger gen- eration and veterans that working together. If an organ- isation has prevalence of a multi-generational work- force it means that the managers and senior leaders must ensure to drive collaboration, understand the needs of different age groups, and focus on the value they can add. With such a mix of age groups, who havedifferent style of working, the onus of creating an ena- bling environment mostly falls on the senior manage- ment. Communication is the key in bridging generation gap.

There are currently six generations living nowa- days all over the world: the Greatest Generation, Silent Generation, Baby Boomers, Generation X, Millennials, and Generation Z. Each generation has its own unique set of characteristics and norms. The Greatest Genera- tion (born 1901-1924) is known for its patriotism, hard workers, and loyalty to institutions. The Millennials(born 1980-2000) are characterized by their depend- ence on technology, detachment from traditional insti- tutions, optimism, and openmindedness. It is no won- der that many people from different generations have a hard time understanding each other.

Generation gap refers to differences in actions, beliefs, interests, and opinions that exist between individuals from different generations (Subramanian, 2017). One factor that has heavily influenced generation gaps is the accelerating rate of change in society.In the 1800 s, developments in society were slow. As a result, two or three generations lived lifestyles that were very similar to each other. There weren't many differences across generations. However, given techno - logical and social advances that have taken place in the 20th and 21 st centuries, the lifestyles of individu- 
alseven one generation apart are drastically different from each other. Usually Baby Boomers always compared to Generation Z, based on the research of Putra (Putra, 2016) for there are significant differences in character- istics between generations $\mathrm{Z}$ with other generations, one of the main factors that distinguish is the mastery of information and technology. For the $Z$ generation information and technology are things that have be-come part of their lives, because they are born where access to information, especially the Internet has be- come a global culture, so that it affects their values, views and life goals.

Let us recall all of the changes in technology that have occurred in the past 20 years. Many individuals from older generations are having trouble keeping up with the modern technologies that Millennials have become accustomed to. Due to generation gaps, a child may explain to an adult how to use technology, or a young adult will choose to spend his time on public transportation texting, while an older man passes the time reading.

The senior generations come with their own brand of wisdom and experience. The senior management can leverage this. Experts say positioning older employees as brand ambassadors of company culture can help in integrating people into the roots of the com - pany. Setting clear role expectations will ensure a fully functional and enabling work environment. Millennials have a thirst to learn and are respectful of older genera- tions.

Regardless of how much we have experiencedor how much degrees we have, there is always more wecan learn. Today's generation can take some great les- sons from the older generations. Lessons to be applied to every aspect of their lives. According to Santrock in (Willyarto, Werhoru, \& Gea, 2017), motivation is why individuals behave, think and have feelings in a way that they do, with emphasis on the activation and direc- tion of behavior. When ones are motivated, they will dosomething, they demonstrated active behavior. For ex- ample, when a child is hungry, they will open the re- frigerator for food. When people are motivated to per- form well, they will learn diligently and independently. People will strive to achieve what they aspire when properly motivated. Motivation focuses on how people behave, or in other words chosen behavior for certain situations but not for other situations. Conversely, to- day's youth can teach the Veterans and Baby Boomers much about technology. Always encourage learning and growth within them, as everything we learn shapes us into the type of individuals we are become. While it may be tempting to bury your head regarding the differ-ences, ignoring these differences only stands to cause resentment and dissension. Instead, acknowledge and embrace the differences. Use them as tools and encour- age your surroundings to use these variances as a chance to learn and grown. At the end of the day, after all, the bonding is strengthening and what they have to offer is unity.

\section{Cross Cultural Communication}

Culture is dynamic, fluid, and complex; culture changes all the time, every day in both subtle and tangi-ble ways; and usually taken for granted. It is dynamic because it represents the experiences, beliefs, and norms of the living people. Culture is always evolving, pushed, stretched, and change, in which communication include in every single step and/ or processes.

Cultural values are the core principles and ideals upon which an entire community exists. This is madeup of several parts: customs, which are traditions and rituals; values, which are beliefs; and culture, which is all of a group's guiding values. Value denotes the de-gree of importance of some thing or action, with theaim of determining what actions are best to do or what way is best to live, or to describe the significance of different actions.

Each time we communicate with another culture, we may stereotype or negatively evaluate their culture and ways of behaving, just as other cultures may judge, stereotype or evaluate our culture/ways of behaving through their own cultural filters (Browaeys\& Price, 2015).

Cross-cultural engagement involves making choices. One choice equates diversity with deficit: assume ours is the mainstream culture and write over any differences with our language and culture; think that there is just one single right way and that this way is natural; assume that if others can"t demonstrate these ways then they are deficit or lacking; and consider dif- 
ferent ways to be inferior, the other. The more culturally aware choice - lies in accepting difference: recognis -ing that our culture is just one of many - not better or worse but different. This choice understands that each cultural group communicates using specific verbal and nonverbal behaviours and that these might differ from our own. This choice also recognises that it is important to develop an awareness of different cultures, their un- derstandings and practices and to acknowledge theirvalue and contributions. An essential feature of the competencies is that they are socially and culturally appropriate or fine-tuned to the particular culture, sub- culture or discourse being engaged.

Social Media - New Media

Social media is interactive computer mediated techniques that facilitate the creators and sharing of information, ideas, career, interests, and other forms of expression through virtual communities and networks. Social media can help people to improve their individu -al sense of connectedness with real communities, off line communities, and can be effective communication tools for corporations, entrepreneur, and non-profit organization or so forth.

New media refers to those digital media that are interactive, incorporate two ways information and involve some form of computing. It is a communication technology that enable or facilitate user to user interactivity, or between user and information.

New media replaced one to many models of traditional or conventional mass media communication with the possibility of many to many webs of communication. One of the examples is Instagram, a mobile

application which have photo and facilitate to sharing social networking services. It is so good for engaging with audiences because it is direct, offering novelty, concise, simple, and light as possible. According to Shih, this is now possible through the social networkingsites across every continent. Social networks became a new powerful kind of marketing channel providing newability to "think global, act local" using „hypertargeting" defined by Shih as ,the ability on social networking sites to target ads on very specific criteria". The adver- tisers who know the demographic and psychographic profiles of the users can focus their ads on what will interest the viewers. Having said this, Shih adds that,social media is a commitment, not a cam-paign ${ }^{c e}$ (Browaeys \& Price, 2015).

\section{RESULTS AND DISCUSSION}

Communicating about manners and cultural values supposed to be started from the family as the first fundament of a person. People belief that a harmonious family is a building block for constructinga harmonious society. Parents begin teaching their children about the concepts of manners and respectful politeness as a crucial thing in building social relationships outside the family.

The emphasis is in controlling natural expressions of feeling and emotion. Being expressive is a highway to cruelty and rude to be exposed amongst people. In general, Javanese children must learn to control any expressive behavior, even leading todisplaying a passive attitude, because they not allowed to express any disagreement with others, especially older persons. In brief, these explanations can shape a contextual understanding of Indonesian society by focusing on three points which this investigation benefits from. First, there exists firm loyalty to the hierarchical relationships within Indonesian society. Second, the leadership criterion in Indonesian society puts emphasis on the importance of seniority. Third, theattitude of controlling individual expressive behavior in social relationships, behavior leading to any disagreement with the senior persons is also given emphasis in Indonesian society in order to facilitateharmony. In general, the concise review of Indonesian society daily can construct specific beliefs and values shared among others.

In addition, due to the research of Sawyer and Chen (Sawyer \& Chen, 2012), the social media could be one of the tools to adapt to the new culture and to make interconnectedness between generation. There is no a shortcut or a kind of secret recipe to balancing the social media and our real life, at the end of the day we must behold our self before the other people. Giving the meaning of self-actualization is done through a process of production of meaning that is managed and organized based on the relationship with 
the management of information or experience as a person. In phenomenological view, the process of stocking knowledge and experiences that influence the meaning constructed in mindset, movement, attitude, and behavior can be applied and implemented in real life. The informants interpreted that starting interaction and doing the convergence is a part of implemented of avoiding assumption. In communication we better ask instead of believe in our own stereotyping. The process of doing all those things supposed to be an actualization of their communication skills through inyeracting, convergencing, and cooperated with the people that tottaly different to them. The experience of cooperation with many people, also influenced the meaning of given in pursuing self-actualization which pays attention to humans, especially to the values of dignity in full. This can be achieved by all potential, talents, and abilities possessed by working as well as possible so that an ideal state of existence is achieved for growth and self-development. Self-actualization is aprocess of being yourself and developing unique psychological traits and potentials. Self-actualization will be helped or even hindered by learning experiences, especially in childhood. Actualization will change with the development of one's life when it reaches a certain age and will experience a shift from physiological to psychological stages.

Everyone has a need for self-actualization to develop all their potential. An image of our self is self - concept. It consists of feelings and thoughts about the strength and weakness, abilities and limitations, aspirations and worldview Self-concept develops from at least four sources: 1. The image of you that others have and that they reveal to you. 2. The comparisons you make between yourself and others. 3 . The culture. 4. The way you interpret and evaluate your own thoughts and behaviors.

Another way to develop self-concept is by comparing our self with others. Through parents, teachers, and media, culture constructing variety of beliefs, values, and attitudes about: success (how you define it and how you should to achieve it); about your religion, race, and nationality; about the ethical principles you should follow in business and in your personal life. These teachings provide benchmarks against ho we measured our self. In our society we face the rules and border of almost everything and must be obey of it, meanwhile societies is cruel and mean, there were an arena or battlefield that representing the limits and co- herence of any good and bad or right and wrong.

The social importance of having a good wholesome self-concept and perfect self-esteem is leading to the concern which will allow women to facing the world simultaneously. The basic idea behind the selfesteem is when you feel good about yourself, aboutwho you are, your competencies and capability, you will perform better.

The perfect self-concept and self-esteem will make women experience more appreciation, more important position, and more advantageous to prosperous; therefore because self-concept and self-esteem are not only the smart weapons or letters of recommendation, but also the transformation from lack to skilfull conver-gencing.

Humans have the potential to grow and develop in a better direction. So, self actualization can be interpreted as the innate desire of individuals to developtheir potential and achieve achievements in accordance with their respective fields. Reputation is a crucial aspect that is worth fighting for, managed and maintained by each institution so that the institution remains strong in the eyes of the public. Reputation institution is howto manage the affairs of an institution with respect to allhis constituents; it is concentrated in the identity orcharacter of the institution. Identity restricts the actions taken by the institution, how they make decisions, treat employees, and react to the crisis. The identity is the backbone of a reputation, and he describes the kind of relationship that built between public institutions with their most important, those are: constituents, employ- ees, customers, investors and local communities. Binus University still maintaining the reputation by continu- ing the skills of their stakeholders and shareholders by their innovation, for example a creative class; the con- cepts of teaching and learning situation in a class, where the lecturer and the students are in the same leveland coul create everything that they want, they candraw and show their mind freely. 
Socialization is preceded by the formation of their mother in rearing them. How do you define what should be done and what is not worth doing, is precisely desired by the environment. Supposedly the distinguished formation which separated gender was not formed since people were in their childhood, because naturally the children will understand what is right and what is wrong, what is good and what is bad; not about what men supposed to do and vice versa.

The cultural dynamic has changed day by day. Communication skill is what lies beneath us. The expertise of cross-cultural communication is a part that constructs attitude that influences intention, and there is a relationship between people attitude with the relationship that built between the lecturers and students, and communities as the cultural dynamics processes. Meanwhile the magic words in social media, culture, and communication is engaged. Engaged as a person to a person, hence no matter how many your followers are or how changed this world could be, we always be still because we are engaged and adjust the latest invention.

Communicators often express values, but the standard, recognized usages within our ordinary language, and that all the interpretations are relevant for understanding intercultural communication. Values are properties we ascribe to actions we think of as ethicallygood or wrong. On the other hand, when we make ethical statements, we do not believe that actions are good or bad in relation to rules in well-defined some contexts. Our intent is to emphasize something that is much more difficult to express but clearly connected to our beliefs about interpersonal relations and the norms that we think other persons should conform to. General beliefs about how people should act typically underlie individuals" ascriptions of value properties to actions.

Cultural value is the concept that usually taken for granted as general concepts which people believe in. We typically think that they should constitute normsnot only for one cultural group or community but also for everyone. In fact, we must try to imagine another person in our own position, in our specific social and cultural context, the researchers should find it almost impossible to imagine how they could be justified in thinking that some of things are not fundamental values.

This does not mean that values understood as abstract concepts are valid from a neutral, objective point of view. Such a point of view does not exist. The important point is that fundamental concepts of value are always experienced as valid from a point of view, woven into a person's social and cultural context.

Disagreement and problems in intercultural interaction can often be explained by showing that people have different concepts of cultural value thatthey believe are fundamental to society. There is, however, another concept of value that is even more relevant for understanding communicative challenges in intercultural interaction. This concept is importance because it is intimately connected to the way individuals wish to live their own lives. This personal feature is in contrast from those values understood as abstract, general concepts. Understanding what values, a person has in this sense is, therefore, equivalent to understanding what beliefs he has. Similarly, the addressing of relevant communicative challenges falls under the more general task of understanding the roleof meaning and belief in communication as explained above. We esteem our personal values; they are essentially connected to our ,forms of life", that is, the interests we have and the activities in which we like to participate.

Understanding what personal cultural values an individual has is, therefore, not equivalent to understanding what general cultural values they believe in. Personal values are radically different from beliefs they are not true or false depending on how the worldis. Instead, they are directly related to actions we make or should like to make in connection to specific circumstances.

When communicators from different cultural contexts interact, values of this kind are often central intheir communication. But since understanding what general concepts a person believes in is equivalent to understanding what beliefs he has, interactions involving general concepts of value do not constitute a communicative challenge that is different in principle from communication of beliefs. Of course, from the perspective of an audience, to understand what concepts 
of value a speaker believes in is sometimes experienced as important, but the point is that if the audiences focus is on the speaker's beliefs, then the focus on the speaker's general concepts of value is included within that broader focus.

Another way of understanding cultural value, however, corresponds to a communicative challenge that is different in principle from communication of beliefs and is especially important in intercultural interaction. The reason is as follows: According to the analysis that have developed, to understand what personal values a person has is tantamount to understanding how he wishes to live his life, and this is not a matter of understanding what thoughts and beliefshe has. Moreover, the fact that persons from different cultures typically live their lives in significantly different ways means that it is especially important to focus on these values in real-life interaction. To understand what personal values we need to realizehow they wishes to live their life. We need to understand what activities the people experience as valuable from their perspective. But if the official hasan entirely different perspective, if the starting points are so radically different and there seems to be so little sympathy for the other person's interests, there will be a formidable problem of communication.

Complete understanding is rational agreement, a comprehensive overlap of beliefs regarding a topic of discourse. It follows that the process of understanding should be thought of as a gradual uncovering of another person's beliefs, and that a good understanding of another person presupposes that there is a significant overlap of common beliefs. Correspondingly, if communicators have very different beliefs about a topicof discourse, then the chances of achieving successful communication about that topic of discourse areradically impaired.

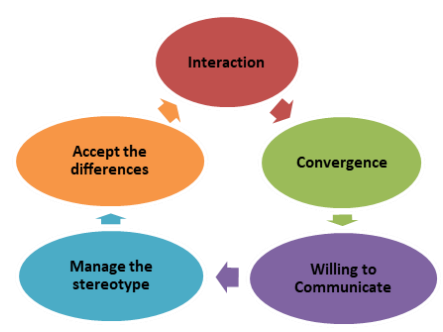

(Cross cultural model based on research results)
That model seems very ideal and have no conflict in it; it is true, because the informants that we observed are the people who willing to build the commu - nication, maintain the interaction and doing the conver- gence. They avoid stereotyping and accept the differ- ences, as there are no one in this world are similar.

\section{CONCLUSION}

People need to share many more beliefs in order to communicate successfully, and this condition is probably not met. However, the problem related to personal values is even more fundamental: when two persons share a belief, then that is because they have a belief involving the same representation of the world Ifpersonal values are relations not to representations, but directly to the ways we wish to live our lives, then they cannot be shared at all.

Every aspect of global communication is influenced by cultural differences. Even the choice of medium used to communicate may have culturalovertones. Culture is, basically, a set of shared values that a group of people holds. Such values affect how you think and act and, more importantly, the kind of criteria by which you judge others. Cultural meanings render somebehaviors as normal or right and strange or wrong.

Every culture has rules that its members take for granted. Few of us are aware of our own biases because cultural imprinting is begun at a very early age. And while some of culture"s knowledge, rules, beliefs, values, phobias and anxieties are taught explicitly, mostis absorbed subconsciously.

Bina Nusantara University bridging the generation gap with creating a creative class through the furniture arrangement and facilitating the openness communication between generation. Nevertheless, a college or university environment need people who willing the learn about diversity all the way, for the lifetime. We are all individuals, and there are no two people belonging to the same culture guaranteed to respond in the same way. However, generalizations are valid to the extent that they provide clues on what you will most likely encounter and how those differences 
impact communication. The most important things to remember and apllied in our daily life based on this research is the willingness to do the communication or doing the interaction instead of assuming and doing the stereotyping.

\section{ACKNOWLEDGEMENT}

This article was funded by the Directorate General of Strengthening for Research and Development, the Ministry of Research, Technology and Higher Education (Kemenristekdikti) of the Republic of Indonesia as part of the Higher Education Leading Research Base Grant for Bina Nusantara University entitled "CROSS CULTURAL COMMUNICATION MODEL IN ACCOMMODATING THE GENERATION GAP OF SOCIAL STRUCTURE IN DISRUPTIVE ERA,"with contract number: 12/ AKM/PNT/2019 and contract date: March 27, 2019.

\section{REFERENCES}

Adiyanto, W. (2020). MEMAHAMI HAMBATAN DOSEN DAN MAHASISWA DALAM PERKULIAHAN ONLINE : FENOMENA ANTISIPASI PENYEBARAN VIRUS COVID-19. Interaksi: Jurnal Ilmu Komu-ni kasi Vol. 9, No. 2 , 98-109.

Barrett, Deborah J. (2014). Leadership Communica tion. Fourth Edition. New York: McGraw-Hill.

Browaeys , M.-J., \& Price, R. (2015). Understanding Cross Cultural Management (3 ed.). Edinburgh Gate, Harlow CM20 2JE, United Kingdom : PEARSON EDUCATION LIMITED.

Bryman, A. (2012). Social Research Methods, Fourth Edition. UK: OUP PRESS

Carter, D. Hustle and Brand: The Sociotechnical Shap ing of Influence. Social Media + Society JulySeptember 2016, pp. 1-12

Chapple, C. and Cownie, F. "An Investigation into Viewers" Trust in and Response Towards Dis closed Paid-for-Endorsements by YouTube Life style Vloggers," Journal of Promotional Com munications, 5 (2), 2017, pp. 110-136

C. Booker, K., \& D. Campbell-Whatley, G. (2018). How Faculty Create Learning Environmentsfor
Diversity and Inclusion. InSight: A Journal of Scholarly Teaching, vol.13, 14-27.

Comperatore, E., \& Nerone, F. (2008). Coping With Different Generations In The Workplace. Jour nal of Business \& Economics Research, Vol.6, No.6, 15-30.

Forbes, K. Examining the Beauty Industry"s Use of Social Influencers. Elon Journal of Un dergradu ate Research in Communications, Vol. 7, No.2 • Fall 2016, pp 78-87

Jones, D.C, ,_Vigfusdottir, T.H.,_Lee , Y. Body image and the appearance culture among adolescent girls and boy: an examination of friend conver sations, peer criticism, appearance magazines, and the internalization of appearance ideals. vol_19,_Issue 3,_2004

Kodikal, R., Rahiman, H. U., \& Bindu. (2017). Cross Cultural Issues and Human Resources Manage ment of Expat. International Journal of Recent Scientific Research Research Vol. 8, Issue, 6, 17834-17840.

Neuman, W. Lawrence. (2013). Social Research Meth ods, Qualitative and Quantitative Approach, Seventh Edition. USA: Pearson Education

Paço, A. \& Oliveira, S. Influence Marketing in the Fashion and Beauty Industry. Estudos em Co municação n ${ }^{\mathrm{o}}$ 25, vol. 1, 2017, pp.119-136

Putra, Y. S. (2016). THEORITICAL REVIEW : TEORI PERBEDAAN GENERASI. Among $M a$ karti Among Makarti Vol.9 No.18, 123-134.

Rapp, FG, "The Digital Media Phenomenon of YouTube Beauty Gurus: The Case of Bub zbeau ty," in International Journal of Web Based Communities, 12(4), 2016, pp. 360-375.

Sawyer, R., \& Chen, G.-M. (2012). The Impact of Social Media on Intercultural Adaptation. Intercultural Communication Studies, vol.21, no.2, 151-169.

Shen, B. \& Bissel, K. Social Media, Social Me: A Content Analysis of Beauty Companies ${ }^{e e}$ Use of Face book in Marketing and Branding. Jour nal of Promotion Management. Vol 19, 2013, pp. 629-651

Sokol, Elizabeth, The world of beauty vloggers on YouTube: The type of endorser, product place 
ment and its effect on perceived credibility, brand attitude and purchase intention of con sumers after watching beauty vlogs on YouTube, Erasmus University, Rotterdam, 2017.

Spade, J. Z., \& Valentine, C. G. The kaleidoscope of gender: Prisms, patterns, and possibilities. Pine Forge Press. 2008.

Subramanian, K. R. (2017). The Generation Gap and Employee Relationship. International Journal of Engineering and Management Research, vol.7, issue 6, 59-67.

Suresh, V et al. A Study on Factors Determining So cial Media on Cosmetic Product. Journals of Pharm. Sci. \& Res. Vol. 8(1), 2016, pp. 1-5 